\title{
Assimilation, multiculturalism, and colorblindness: Mediated and moderated relationships between social dominance orientation and prejudice
}

\section{Citation}

Levin, Shana, Miriam Matthews, Serge Guimond, Jim Sidanius, Felicia Pratto, Nour Kteily, Eileen V. Pitpitan, and Tessa Dover. 2012. "Assimilation, Multiculturalism, and Colorblindness: Mediated and Moderated Relationships Between Social Dominance Orientation and Prejudice." Journal of Experimental Social Psychology 48 (1) (January): 207-212. doi:10.1016/j.jesp.2011.06.019. .

\section{Published Version}

doi:10.1016/j.jesp.2011.06.019

\section{Permanent link}

http://nrs.harvard.edu/urn-3:HUL.InstRepos:14302020

\section{Terms of Use}

This article was downloaded from Harvard University's DASH repository, and is made available under the terms and conditions applicable to Open Access Policy Articles, as set forth at http:// nrs.harvard.edu/urn-3:HUL.InstRepos:dash.current.terms-of-use\#OAP

\section{Share Your Story}

The Harvard community has made this article openly available.

Please share how this access benefits you. Submit a story.

Accessibility 
Assimilation, Multiculturalism, and Colorblindness: Mediated and Moderated Relationships between Social Dominance Orientation and Prejudice

\author{
Shana Levin, Claremont McKenna College \\ Miriam Matthews, Claremont Graduate University \\ Serge Guimond, Universite Blaise Pascal \\ Jim Sidanius, Harvard University \\ Felicia Pratto, University of Connecticut \\ Nour Kteily, Harvard University \\ Eileen V. Pitpitan, University of Connecticut \\ Tessa Dover, Claremont McKenna College
}

Abstract: 150 words

Text and footnote: 4,996 words

\begin{abstract}
Author Note
Correspondence concerning the article should be addressed to Shana Levin, Claremont McKenna College, Department of Psychology, 850 Columbia Avenue, Claremont, CA 91711; e-mail: slevin@cmc.edu; phone: (909) 607-5089; fax: (909) 6218419.
\end{abstract}




\begin{abstract}
Using correlational and experimental data, we examined the degree to which personal and perceived normative support for the acculturation ideologies of assimilation, multiculturalism, and colorblindness mediated and moderated the relationship between social dominance orientation (SDO) and prejudice among 299 White students at three American colleges. Correlational results indicated that personal support for the acculturation ideologies mediated the SDO-prejudice relationship. Personal support for assimilation (a hierarchy-enhancing ideology) positively related to SDO; multiculturalism and colorblindness (hierarchy-attenuating ideologies) negatively related to SDO. An experimental manipulation varied whether assimilation, multiculturalism, or colorblindness was considered normative in the United States. In addition to a control, a fifth condition primed the Obama presidency. SDO related most strongly to prejudice toward American immigrants and ethnic minorities when assimilation norms and the Obama presidency were primed. Efforts to reduce the associations between SDO and prejudice are discussed in terms of highlighting hierarchy-attenuating national norms of multiculturalism and colorblindness.
\end{abstract}

Keywords: assimilation; multiculturalism; colorblindness; social dominance orientation; prejudice. 
Assimilation, Multiculturalism, and Colorblindness: Mediated and Moderated Relationships between Social Dominance Orientation and Prejudice

"Give me your tired, your poor, Your huddled masses yearning to breathe free, The wretched refuse of your teeming shore. Send these, the homeless, tempest-tossed to me, I lift my lamp beside the golden door!"

Emma Lazarus, “The New Colossus" (1883)

Emma Lazarus' famous words, engraved on the Statue of Liberty, greeted thousands of American immigrants. Contrary to the poem's hopeful intent, many different ethnic and cultural groups have experienced prejudice and discrimination in American society. According to social dominance theory, a major factor driving group prejudice is social dominance orientation (SDO). SDO captures individuals' support for hierarchical relationships among societal groups. Those high in SDO want to establish and maintain power differences between groups; one way they may do so is by denigrating subordinate groups (e.g., Levin \& Sidanius, 1999). People who experience prejudice and discrimination suffer many negative outcomes, including poorer mental and physical health (e.g., Landrine \& Klonoff, 1996). These negative outcomes reinforce their subordinate position in American society. Acts of prejudice can thereby serve the desires of high SDO individuals to maintain group-based inequality.

Although the link between SDO and prejudice has been studied extensively (e.g., Sibley \& Duckitt, 2008), personal and normative beliefs that might mediate and moderate the SDO-prejudice relationship have received less empirical attention. In the current study, we measure and manipulate personal and perceived normative support for the three acculturation ideologies of assimilation, multiculturalism, and colorblindness in order to 
better understand their role in mediating and moderating the relationships between SDO and prejudice toward minority groups among Whites in the United States.

\section{Social Dominance Theory}

According to social dominance theory, hierarchies can be enhanced or attenuated by both personal and normative support for legitimizing ideologies. Legitimizing ideologies can be classified into two different functional types: hierarchy-enhancing and hierarchy-attenuating (Pratto, Sidanius, \& Levin, 2006; Sidanius \& Pratto, 1999). Hierarchy-enhancing ideologies facilitate greater levels of group-based social inequality; hierarchy-attenuating ideologies promote increased social equality. Research on social dominance theory has typically focused on the hierarchy-enhancing or hierarchyattenuating role of personal support for legitimizing ideologies. Less empirical attention has focused on the role of the normative context in enhancing or attenuating hierarchies.

Normative context. One study found that the relationship between SDO and group identification varied as a function of the hierarchy-enhancing or hierarchyattenuating nature of the social context (Levin, Sinclair, Sidanius, \& Van Laar, 2009). Based on evidence demonstrating the hierarchy-enhancing nature of unequal ethnic relations in American society, the researchers predicted and found an asymmetrical relationship between SDO and group identification across dominant and subordinate ethnic groups: SDO and ethnic identification were positively related among White university students but negatively related among Asian, Latino, and African American students. However, when the students' identification with the larger university was assessed (a hierarchy-attenuating university environment within which group equality was emphasized), SDO was largely unrelated to university identification among both 
dominant and subordinate group members. This previous research suggests that SDO functions to preserve hierarchies in hierarchy-enhancing contexts: high SDO individuals support dominant group identities and reject subordinate group identities. But in hierarchy-attenuating contexts, SDO does not function to differentially promote group identities in ways that maintain the superiority of the dominant group. Therefore, SDO may be less related to group-relevant outcomes in hierarchy-attenuating contexts than in hierarchy-enhancing contexts.

In the current study, we propose that the relationship between SDO and prejudice will vary as a function of the hierarchy-enhancing or hierarchy-attenuating nature of the acculturation ideologies that are considered normative in a particular social context. In general, high SDO individuals will strive to establish and maintain group hierarchies. But they are constrained by social reality. In hierarchy-enhancing contexts, in which people are normatively viewed as behaving in ways that promote group hierarchy, high SDO individuals will perceive the social hierarchy to be especially worth promoting. Under these circumstances, SDO should be more instrumental in driving prejudice against subordinate groups in order to preserve the hierarchical structure. Conversely, in hierarchy-attenuating contexts, in which people are normatively viewed as behaving in ways that promote group equality, endorsing counter-normative prejudicial attitudes and behaviors will not be as instrumental in helping high SDO individuals attain the desired hierarchy. As such, we hypothesize that the SDO-prejudice relationship will be stronger when hierarchy-enhancing acculturation ideologies are considered normative than when hierarchy-attenuating ideologies are normative. Previous research has found that the level of perceived consensus about prejudice and stereotypes influences the expression of 
prejudice (Crandall, Eshelman, \& O’Brien, 2002; Sechrist \& Stangor, 2001) and stereotype endorsement (Stangor, Sechrist, \& Jost, 2001). If we can establish that ideological context affects the SDO-prejudice relationship, we would have further evidence regarding the functional role of SDO in contributing to intergroup inequality.

Personal support for ideologies. In order to test our hypothesis regarding the role of ideological context in moderating the relationship between SDO and prejudice, we must determine whether the acculturation ideologies of assimilation, multiculturalism, and colorblindness are hierarchy-enhancing or hierarchy-attenuating. In principle, assimilation involves the blending of majority and minority cultural characteristics into a unique combination that creates a shared national identity. In practice, however, assimilation in the United States has typically involved the abandonment of minoritygroup particularisms and adoption of majority-group cultural characteristics as the basis for American identity (Davies, Steele, \& Markus, 2008; Gordon, 1964; Taylor \& Moghaddam, 1994). As such, Guimond et al. (2011) have argued that assimilation is a hierarchy-enhancing ideology, promoting the dominant position of majority group members by using their cultural characteristics to define the national identity. By contrast, multiculturalism promotes the maintenance of each ethnic group's cultural heritage (Berry, 2006; Taylor \& Moghaddam, 1994). As a policy that specifically recognizes and promotes the unique cultural characteristics of all ethnic groups, multiculturalism is hierarchy-attenuating in nature; all ethnic groups are equally valued and contribute to American identity.

Colorblindness is a third ideology that has gained momentum in the United States (Plaut, 2010). Proponents of colorblindness propose that the cultural characteristics of all 
groups should be abandoned so that all people are treated equally as individuals rather than as members of particular cultural groups. When viewed as an ideology promoting equal treatment regardless of group membership, colorblindness can be considered hierarchy-attenuating in nature, at least in principle (but see Knowles, Lowery, Hogan, \& Chow, 2009a, for conditions under which colorblindness can serve inegalitarian purposes). Consistent with the notion that the principles of colorblindness and multiculturalism have in common an egalitarian orientation that contrasts with the inegalitarian nature of assimilation, researchers have found that personal support for multiculturalism and colorblindness positively correlate with each other and negatively relate to SDO; personal support for assimilation, by contrast, negatively correlates with both support for multiculturalism and colorblindness and positively relates to SDO (Guimond et al., 2011; Knowles et al., 2009a; Ryan et al., 2007; Wolsko, Park, \& Judd, 2006).

This previous research provides one piece of evidence regarding the nature of the acculturation ideologies, but research on social dominance theory has established a second criterion for determining whether an ideology is hierarchy-enhancing or hierarchy-attenuating (Sidanius, Levin, Federico, \& Pratto, 2001). In addition to personal support for hierarchy-enhancing ideologies relating positively to SDO and hierarchyattenuating ideologies relating negatively to SDO, the ideologies must mediate the relationship between SDO and attitudes and behaviors that enhance or attenuate the social hierarchy. For example, if such ideologies function to promote or reduce prejudice in order to serve general desires for group dominance or equality, respectively, personal support for the ideologies should mediate the relationship between SDO and prejudice. 
Although previous research has examined the associations between SDO and prejudice, and between SDO and acculturation ideologies, the functional role of personal support for acculturation ideologies in mediating the relationship between SDO and prejudice has not been established.

\section{The Current Study}

Researchers have distinguished between assimilation and multiculturalism (e.g., Wolsko et al., 2006) and between multiculturalism and colorblindness (e.g., Plaut, Thomas, \& Goren, 2009; Ryan et al., 2007). We consider all three ideologies simultaneously (see also Guimond et al., 2011). We expect to find that personal support for assimilation is hierarchy-enhancing: it should positively relate to SDO and mediate the SDO-prejudice relationship. By contrast, personal support for multiculturalism and colorblindness should be hierarchy-attenuating: both ideologies should negatively relate to SDO and mediate the SDO-prejudice relationship.

These mediation analyses will allow us to determine the hierarchy-enhancing or hierarchy-attenuating nature of the acculturation ideologies. Then, an experimental manipulation of which acculturation ideology is considered normative in the United States will allow us to test whether the SDO-prejudice relationship is stronger in a hierarchy-enhancing normative context (assimilation) than in a hierarchy-attenuating context (multiculturalism or colorblindness). Also of interest to us are the potentially hierarchy-enhancing or hierarchy-attenuating effects of normative political contexts. As such, in addition to a control condition, we also include an exploratory condition in which we prime the Obama presidency. Some have argued that the Obama presidency has brought on a period of post-racialism, an era in which race no longer matters 
(McWhorter, 2008; Nagourney, 2008). If priming the Obama presidency evokes a hierarchy-attenuating context in which everyone is treated equally, regardless of group membership, then it should weaken the SDO-prejudice relationship. Others have argued that the Obama presidency has spurred some opposition motivated by racism (FrankeRuta, 2009) and even some support motivated by desires to reinforce the hierarchyenhancing claim that racism has been eliminated in America (Knowles, Lowery, \& Schaumberg, 2009b). If priming the Obama presidency evokes such a hierarchyenhancing context, then it should strengthen the SDO-prejudice relationship. We conduct exploratory analyses to examine how priming the Obama presidency might influence the SDO-prejudice relationship.

\section{Method}

\section{Participants and Procedure}

Participants were 299 White students (166 women and 133 men) at three different colleges in California $(n=124)$, Connecticut $(n=121)$, and Massachusetts $(n=54)$. In order to separately evaluate personal support for the acculturation ideologies and also manipulate normative information about them, participants were told that two separate studies were being conducted (for which they would receive separate research participation credit for their lower-division psychology classes). The first was described as a survey study (our measure of personal beliefs) and the second as a study about a news article (our manipulation of normative conditions). At the end of the first study, participants completed a number of unrelated measures (including demographic information). They were then asked to read a new informed consent form inviting them to participate in the ostensibly unrelated second study. 


\section{Survey Measurement of Personal Beliefs}

Students in California and Connecticut completed paper-and-pencil surveys; students in Massachusetts completed the surveys online. Participants indicated the extent to which they agreed or disagreed with a series of statements on a scale from 1 (Strongly disagree) to 7 (Strongly agree). Items measuring each construct were averaged into scales, with higher numbers indicating greater levels of the constructs. Twelve items adapted from Guimond et al. (2011) for the American context were used to assess three acculturation ideologies.

Support for assimilation was measured using three items: (1) People who come to the US should change their behavior to be more like Americans, (2) Foreigners should try harder to adapt to American cultural traditions if they want to stay in the US, and (3) The unity of this country is weakened by people of different ethnic and cultural backgrounds sticking to their old ways $(\alpha=.80)$. Support for multiculturalism was measured with three items: (1) We should help ethnic and racial minorities preserve their cultural heritage in the US, (2) Immigrant parents must encourage their children to retain the culture and traditions of their homeland, and (3) A society that has a variety of ethnic and cultural groups is more able to tackle new problems as they occur $(\alpha=.59)$. Support for colorblindness was measured using six items: (1) We should treat citizens of this country as Americans and not as members of particular ethnic, religious or sexual communities; (2) I do not want Americans to be identified by their race, national origin, or religion; (3) American society is made up first and foremost of citizens, not of groups; (4) For the unity of the country, individuals should be considered Americans before any consideration is given to their race or religion; (5) It's best to judge one another as 
individuals rather than members of an ethnic group; and (6) It's important to recognize that people are basically the same regardless of their ethnicity $(\alpha=.77)$.

Social dominance orientation was measured with a balanced, 10-item scale adapted from Pratto, Sidanius, Stallworth, and Malle (1994; $\alpha=.88)$. Generalized prejudice was assessed with four items asking participants to indicate their general attitude toward (1) Blacks, (2) Asians, (3) Arabs, and (4) Muslims (1 = Very unfavorable, $7=$ Very favorable). The four items were reverse-coded and averaged, with higher numbers indicating more negative attitudes $(\alpha=.88)$.

\section{Experimental Manipulation of Normative Conditions}

Upon completion of the survey and new informed consent form, participants were randomly assigned to read one of five articles ostensibly published on November 18 , 2008 by an online news source. The articles described five different versions of the results of a telephone survey of over 3,200 Americans. In the assimilation, multiculturalism, and colorblindness conditions, the articles manipulated consensus regarding which acculturation condition is considered normative in American society. The survey results were described as clearly showing that most Americans are: (1) integrating into one national group rather than emphasizing their identities as individuals or members of cultural groups (assimilation), (2) emphasizing their memberships in particular cultural groups rather than their identities as separate individuals or Americans as a larger group (multiculturalism), or (3) emphasizing their identities as separate individuals rather than as members of particular cultural groups or Americans as a larger group (colorblindness). In the Obama condition, the article described the survey results as revealing "a widespread perception that Obama will address the political and economic 
issues he discussed in his campaign." In the control condition, the widespread perception revealed by the survey results was that "advancements in technology have made life easier."

After reading the article, participants were asked how well they thought people's views on the topic of the poll were captured by the article $(1=$ Not at all, $7=$ Very much $)$. With this variable as the dependent measure, a one-way ANOVA by experimental condition was significant, $F(4,294)=5.57, p<.001$. Post hoc tests revealed that the control $(M=4.52, S D=1.27)$ and Obama $(M=4.20, S D=1.34)$ means were significantly higher than the assimilation mean $(p \mathrm{~s}<.05)$, but participants in the three acculturation conditions did not significantly differ in terms of how well they thought people's views were captured by the article ( $p \mathrm{~s}>.05$; colorblindness $M=4.12, S D=$ 1.53; multiculturalism $M=3.87, S D=1.33$; assimilation $M=3.41, S D=1.25)$.

Following the article, participants completed several measures. SDO was assessed with a balanced, 4 -item scale $(\alpha=.78) .{ }^{1}$ Group prejudice was measured by asking participants to indicate their general attitude toward members of the following groups $(1=$ Very unfavorable, 7 = Very favorable; reverse-coded $)$ : Latino/Hispanic Americans, Asian Americans, African Americans, Arab Americans, and immigrants to the U.S. In addition to serving as separate measures of group prejudice, the five items were also averaged together to form a composite measure of generalized prejudice $(\alpha=$ 92). Ethnic identification was included as a control variable in the analyses. It was measured immediately after participants indicated that the ethnic/cultural group with which they most closely identified was "Caucasian, non-Hispanic.” They were asked three questions assessing their identification with this group: How strongly do you 
identify with this group? How important is it to you to be a member of this group? How close do you feel to other members of this group? $(1=$ Not at all, $7=$ Very $m u c h ; \alpha=$ $.88)$.

\section{Results}

\section{Mediation of the SDO-Prejudice Relationship: Personal Support for Ideologies}

Means, standard deviations, and correlations among all measures in the initial survey study are shown in Table 1. A repeated-measures ANOVA indicated that personal support for colorblindness was highest, followed by multiculturalism and assimilation, $F(2,297)=187.03, p<.001$; all pairwise comparisons were significant, $p \mathrm{~s}$ $<.001$. Correlational analyses revealed that higher levels of SDO were associated with greater generalized prejudice. SDO also positively correlated with support for assimilation, but negatively related to support for multiculturalism and colorblindness. Higher support for assimilation, lower support for multiculturalism, and lower support for colorblindness were associated with more generalized prejudice.

We next examined a path model with SDO predicting personal support for each acculturation ideology and the acculturation ideologies predicting generalized prejudice (see Figure 1). We tested this model using maximum likelihood estimation of parameters with AMOS 16.0. The model demonstrated a good fit to the data $\left(\chi^{2}=5.20, d f=2, p\right.$ $=.07, \mathrm{CFI}=.99, \mathrm{RMSEA}=.07)$. The direct effect of SDO on generalized prejudice was not significant $(\beta=.05, p=.39)$. Personal support for assimilation $(\beta=.29, p<.001)$, multiculturalism $(\beta=-.21, p<.001)$, and colorblindness $(\beta=-.18, p<.001)$ were all significant predictors of prejudice. 
We then conducted tests of the model's indirect effects of SDO on generalized prejudice through the acculturation ideologies. We computed the point estimates of the total indirect effect of SDO on generalized prejudice as well as the separate indirect effects through each ideology. The point estimates and $z$-values of the indirect effects were derived from a product-of-coefficients approach using the multivariate delta method (Preacher \& Hayes, 2008). The total indirect effect of SDO through all three acculturation ideologies was significant (point estimate $=.23, z=5.71, p<.001$ ). When considered simultaneously, support for assimilation (point estimate $=.12, z=3.76, p<$ .001 ), multiculturalism (point estimate $=.07, z=2.84, p=.005$ ), and colorblindness (point estimate $=.04, z=2.46, p=.01$ ) each significantly mediated the relationship between SDO and generalized prejudice.

As expected, these analyses indicated that personal support for assimilation is hierarchy-enhancing and support for multiculturalism and colorblindness is hierarchyattenuating. However, a plausible rival hypothesis is that generalized prejudice mediates the relationships between SDO and personal support for the three acculturation ideologies. We tested this alterative notion in a model in which SDO directly predicted generalized prejudice, which subsequently predicted support for the three acculturation ideologies. This alternative model did not provide as good a fit to the data $\left(\chi^{2}=79.19, d f\right.$ $=4, p<.001, \mathrm{CFI}=.70, \mathrm{RMSEA}=.25)$ and showed a significant deterioration in model fit $\left(\chi_{\text {diff }}^{2}=73.99, d f=2, p<.001\right)$.

Taken together, these analyses reinforce the notion that high SDO Whites support the hierarchy-enhancing ideology of assimilation and oppose the hierarchy-attenuating ideologies of multiculturalism and colorblindness as a way of justifying greater prejudice 
against other cultural groups. Now that the hierarchy-enhancing or hierarchy-attenuating nature of the acculturation ideologies has been established, we examine whether experimentally manipulating the normative ideological context strengthens the SDOprejudice relationship in a hierarchy-enhancing context (assimilation) relative to hierarchy-attenuating contexts (multiculturalism and colorblindness). We also explore the nature of the SDO-prejudice relationship in the potentially hierarchy-enhancing or hierarchy-attenuating political context of the Obama presidency.

\section{Moderation of the SDO-Prejudice Relationship: Normative Ideological Context}

Table 2 reveals the product-moment correlations between SDO and the prejudice measures, as well as between SDO and White ethnic identification, across the experimental conditions. Previous research has shown that SDO relates positively to ethnic identification among members of high-status groups (e.g., Levin \& Sidanius, 1999). To control for the possibility that the greater ethnic identification of high SDO Whites is driving the relationships between SDO and prejudice, Table 2 also provides unstandardized regression coefficients for the relationships between SDO and the prejudice measures controlling for ethnic identification.

We expected to find stronger relationships between SDO and the prejudice measures in the assimilation condition than in the multiculturalism and colorblindness conditions. The regression coefficients supported our expectations in the assimilation condition: Higher levels of SDO were strongly and significantly associated with more prejudice toward Latinos, Asian Americans, African Americans, Arab Americans, and U.S. immigrants. The relationship between SDO and generalized prejudice was also positive, strong, and statistically significant. The regression coefficients revealed a 
different pattern in the multiculturalism condition: Higher levels of SDO were significantly associated with more prejudice toward Arab Americans and U.S. immigrants, but not prejudice toward Latinos, Asian Americans, or African Americans. The relationship between SDO and generalized prejudice was positive, but modest and only marginally significant. Results in the colorblindness condition fully supported our predictions: None of the regression coefficients were statistically significant.

To compare the strength of the relationships across the hierarchy-enhancing assimilation context and each of the hierarchy-attenuating contexts (colorblindness and multiculturalism), we first compared the assimilation and colorblindness conditions. We conducted hierarchical multiple regression analyses with data from these two conditions only. SDO and a dummy variable for article condition were entered in Step 1 (with ethnic identification as a covariate) and their two-way product term was entered in Step 2. The prejudice measures were the dependent variables, one in each analysis. The SDO $\times$ condition interaction was a statistically significant predictor of generalized prejudice $\left(\mathrm{R}_{\text {change }}^{2}=.05, p=.02\right)$, prejudice toward Latinos $\left(\mathrm{R}_{\text {change }}^{2}=.04, p=.04\right)$, Asian Americans $\left(\mathrm{R}_{\text {change }}^{2}=.06, p=.01\right)$, and Arab Americans $\left(\mathrm{R}_{\text {change }}^{2}=.04, p=.03\right)$, and a marginally significant predictor of prejudice toward African Americans $\left(\mathrm{R}^{2}\right.$ change $=.02, p$ $=.09)$ and U.S. immigrants $\left(\mathrm{R}_{\text {change }}^{2}=.03, p=.06\right)$. These results demonstrate weaker relationships between SDO and prejudice toward each of the five groups in the colorblindness condition than the assimilation condition. Similar analyses comparing the assimilation and multiculturalism conditions revealed that the SDO-prejudice relationship was weaker under multiculturalism than assimilation for prejudice toward the three groups typically addressed in the rhetoric of multiculturalism: Latinos $\left(\mathrm{R}_{\text {change }}^{2}=.03, p=\right.$ 
$.05)$, Asian Americans $\left(\mathrm{R}_{\text {change }}^{2}=.03, p=.06\right)$, and African Americans $\left(\mathrm{R}_{\text {change }}^{2}=.04, p=\right.$ .02). SDO related strongly to prejudice toward Arab Americans and U.S. immigrants in both conditions $\left(\mathrm{R}_{\text {change }}^{2}=.01, p=.36 ; \mathrm{R}_{\text {change }}^{2}=.00, p=.87 ;\right.$ respectively $)$. The overall relationship between SDO and generalized prejudice did not significantly differ across the assimilation and multiculturalism conditions $\left(\mathrm{R}_{\text {change }}^{2}=.02, p=.11\right)$. Comparisons across all five experimental conditions indicated a significant difference only for the relationship between SDO and prejudice toward Asian Americans $\left(\mathrm{R}_{\text {change }}^{2}=.04, p=.02\right)$ and a marginally significant difference for the SDO-generalized prejudice relationship $\left(\mathrm{R}_{\text {change }}^{2}=.02, p=.10\right)$.

The exploratory analyses in the Obama condition revealed a pattern similar to the assimilation pattern: Higher levels of SDO were strongly and significantly associated with more prejudice toward Latinos, Asian Americans, African Americans, Arab Americans, and U.S. immigrants (see Table 2). The relationship between SDO and generalized prejudice was also positive, strong, and statistically significant. Post hoc hierarchical multiple regression analyses contrasting the Obama and assimilation conditions revealed non-significant interactions between SDO and condition for each of the prejudice measures $(p s>.10)$.

\section{Discussion}

We measured and manipulated personal and perceived normative support for hierarchy-enhancing and hierarchy-attenuating acculturation ideologies to address two issues. First, social dominance theory specifies an empirical test to establish whether an ideology is hierarchy-enhancing or hierarchy-attenuating, determined by the sign of significant mediational relations between SDO and intergroup outcomes, in this case 
generalized prejudice. Second, we examined whether the relationship between SDO and prejudice is moderated by the hierarchy-enhancing or hierarchy-attenuating nature of the normative ideological context. We hypothesized that in hierarchy-enhancing contexts, people with high SDO will express more prejudice because it functions to keep subordinate groups in their inferior position and maintain the desired hierarchy. We did not expect prejudice to be as strongly predicted by SDO in hierarchy-attenuating contexts, either when all people are treated equally as separate individuals (in the case of colorblindness) or as separate cultural groups (in the case of multiculturalism).

Our results showed assimilation to be a hierarchy-enhancing ideology in the United States. Personal support for assimilation was positively associated with SDO, associated with more generalized prejudice, and mediated the relationship between SDO and prejudice. The higher Whites' levels of SDO, the more prejudice they exhibited toward other cultural groups when they personally endorsed the notion that "foreigners should adapt to American cultural traditions," traditions in which the American system of dominance and subordination is firmly entrenched. As assimilation promotes the cultural values of the dominant ethnic group in the blended national identity, it will appeal to high SDO individuals. The more they endorse it, the more negatively they will feel toward groups whose cultural characteristics they do not want preserved in the national identity. An alternative model is that personal support for assimilation and the other acculturation ideologies follows prejudice rather than precedes it. While plausible, this alternative model did not fit the data as well.

High SDO Whites also responded to the portrayal of assimilation as the dominant national norm by expressing more prejudice toward minority groups. Our results imply 
that when minority groups are portrayed as melting their characteristics into those of the dominant group, high SDO Whites will want to emphasize the superior position of the dominant group in the blended national American identity. They will therefore respond to this melting-pot normative context by exhibiting more prejudice toward groups they believe should maintain a subordinate position in American society: immigrants, Arab Americans, African Americans, Asian Americans, and Latinos.

Multiculturalism, by contrast, is a hierarchy-attenuating ideology. Personal support for multiculturalism was negatively associated with SDO, associated with less generalized prejudice, and mediated the relationship between SDO and prejudice. Interestingly, when the U.S. was portrayed as a multicultural context, the associations between SDO and prejudice toward the three specific ethnic minority groups typically addressed in the rhetoric of multiculturalism- African Americans, Latinos, and Asian Americans - were no longer statistically significant. What remained significant were the positive associations between SDO and prejudice toward Arab Americans and U.S. immigrants. Multiculturalism may be an especially potent ideology for promoting equality among groups whose cultural characteristics are explicitly recognized and valued within a society, but people may not generalize such egalitarianism to other groups. As such, future research should continue to examine the effects of normative ideological contexts on prejudice toward different groups. Our measure of generalized prejudice, although a reliable and potent measure of overall prejudice, masked the differences we found in the SDO-prejudice relationship across different groups in the multiculturalism condition. If hierarchy-attenuating ideologies such as multiculturalism embrace some groups more than others and are perceived to be normative, the SDO-prejudice 
relationship may break down only for prejudice toward groups who are explicitly included within the ideology's egalitarian embrace.

Results also showed colorblindness to be hierarchy-attenuating. Like multiculturalism, personal support for colorblindness was negatively associated with SDO, associated with less generalized prejudice, and mediated the relationship between SDO and prejudice. The associations between SDO and prejudice were also consistently weaker in the colorblindness condition than the assimilation condition. This implies that high SDO Whites may be willing to let go of group prejudice as a hierarchy-enhancing strategy when they think people care more about their identities as individuals than as members of a blended national group. These analyses extend social dominance theory by showing how perceived normative contexts causally influence the extent to which prejudice is predicted by SDO (see also Pratto, Tatar, \& Conway-Lanz, 1999). When people are perceived to be normatively viewed as individuals rather than as members of a blended national group, the well-established relationship between SDO and prejudice breaks down. At least under these hierarchy-attenuating conditions, we now have experimental evidence that SDO does not inevitably lead to prejudice (see also Thomsen, Green, \& Sidanius, 2008). We would expect to find these relationships whenever colorblindness serves hierarchy-attenuating purposes (see Knowles et al., 2009a, for conditions under which it serves hierarchy-enhancing purposes instead).

Finally, exploratory analyses revealed that the positive associations between SDO and the prejudice measures were consistently strong in the Obama condition. Contrary to the view that the Obama presidency has ushered in a hierarchy-attenuating, post-racial era, the Obama presidency may have the opposite effect on high SDO Whites (see also 
Knowles et al., 2009b). In the Obama presidency, high SDO Whites may perceive a threat to the dominant position of Whites in American society. In response, they may exhibit more prejudice toward the minority groups they believe should be kept in a subordinate position in the American ethnic hierarchy. High SDO Whites may therefore respond to the ideological context of assimilation and political context of the Obama presidency by exhibiting more prejudice toward groups whose cultural characteristics they do not want preserved in the national identity (in the case of assimilation) and who they fear may follow the precedent set by Obama and advance into positions of power.

Taken together, the results highlight the importance of examining ideological and political contexts in prejudice expression. The extent to which the present findings obtained in the United States generalize to other countries where people are wrestling with similar issues of cultural diversity is an important question for further research. Personal support for hierarchy-enhancing ideologies such as assimilation may indeed be a pervasive vehicle through which desires for social dominance translate into prejudice; and increasing their perceived normative support may strengthen the SDO-prejudice relationship. As such, efforts to reduce the detrimental role of SDO in driving prejudice may be more successful when national norms of colorblindness and multiculturalism are emphasized over norms of assimilation. Such efforts may help to achieve in practice the hierarchy-attenuating principles of colorblind and multicultural ideologies. 


\section{References}

Berry, J.W. (2006). Mutual attitudes among immigrants and ethnocultural groups in Canada. International Journal of Intercultural Relations, 30, 719-734.

Crandall, C. S. Eshleman, A., \& O’Brien, L. (2002). Social norms and the expression and suppression of prejudice: The struggle for internalization. Journal of Personality and Social Psychology, 82, 359-378.

Davies, P.G., Steele, C.M., \& Markus, H. R. (2008). A nation challenged: The impact of foreign threat on America's tolerance for diversity. Journal of Personality and Social Psychology, 95, 308-318.

Franke-Ruta, G. (2009, November 16). Carter cites 'racism inclination' in animosity toward Obama. The Washington Post. Retrieved from http://www.washingtonpost.com

Gordon, M. M. (1964). Assimilation in American life. New York: Oxford University Press.

Guimond, S., Crisp, R. J., De Oliveira, P., Kamiejski, R., Kteily, N., Kuepper, B., Lalonde, R. N., Levin, S., Pratto, F., Tougas, F., Sidanius, J., \& Zick, A. (2011). Cultural models of integration and anti-immigrant prejudice. Manuscript in preparation.

Knowles, E. D., Lowery, B. S., Hogan, C. M., \& Chow, R. M. (2009a). On the malleability of ideology: Motivated construals of color blindness. Journal of Personality and Social Psychology, 96, 857-869. 
Knowles, E. D., Lowery, B. S., \& Schaumberg, R. L. (2009b). Anti-egalitarians for Obama? Group-dominance motivation and the Obama vote. Journal of Experimental Social Psychology, 45, 965-969.

Landrine, H. \& Klonoff, E. A. (1996). The Schedule of Racist Events: A measure of racial discrimination and a study of its negative physical and mental health consequences. Journal of Black Psychology, 22, 144-168.

Levin, S. \& Sidanius, J. (1999). Social dominance and social identity in the United States and Israel: Ingroup favoritism or outgroup derogation? Political Psychology, 20, 99-126.

Levin, S., Sinclair, S., Sidanius, J., \& Van Laar, C. (2009). Ethnic and university identities across the college years: A common in-group identity perspective. Journal of Social Issues, 65, 287-306.

McWhorter, J. (2008, December 30). Racism in America is over. Forbes Magazine. Retrieved from http://www.forbes.com

Nagourney, A. (2008, November 5). Obama elected president as racial barrier falls. The New York Times. Retrieved from http://www.nytimes.com

Plaut, V.C. (2010). Diversity science: Why and how difference makes a difference. Psychological Inquiry, 21, 77-99.

Plaut, V. C., Thomas, K. M., \& Goren, M. J. (2009). Is multiculturalism or color blindness better for minorities? Psychological Science, 20, 444-446.

Pratto, F., Sidanius, J., \& Levin, S. (2006). Social dominance theory and the dynamics of intergroup relations: Taking stock and looking forward. European Review of Social Psychology, Vol. 17, pp. 271-320. 
Pratto, F., Sidanius, J., Stallworth, L. M., \& Malle, B. F. (1994). Social dominance orientation: A personality variable predicting social and political attitudes. Journal of Personality and Social Psychology, 67, 741-763.

Pratto, F., Tatar, D., \& Conway-Lanz, S. (1999). Who gets what and why? Determinants of social allocations. Political Psychology, 20, 127-150.

Preacher, K.J., \& Hayes, A.F. (2008). Asymptotic and resampling strategies for assessing and comparing indirect effects in multiple mediator models. Behavior Research Methods, 40, 879-891.

Ryan, C.S., Hunt, J.S., Weibe, J.A., Peterson, C.R., \& Casas, J.F. (2007). Multicultural and colorblind ideology, stereotypes, and ethnocentrism among Black and White Americans. Group Processes and Intergroup Relations, 10, 617-637.

Sechrist, G. B. \& Stangor, C. (2001). Perceived consensus influences intergroup behavior and stereotype accessibility. Journal of Personality and Social Psychology, 80, 645-654.

Sibley, C. G. \& Duckitt, J. (2008). Personality and prejudice: A meta-analysis and theoretical review. Personality and Social Psychology Review, 12, 248-279.

Sidanius, J. Levin, S., Federico, C. M., \& Pratto, F. (2001). Legitimizing ideologies: The social dominance approach. In J. T. Jost \& B. Major (Eds.), The psychology of legitimacy: Emerging perspectives on ideology, justice, and intergroup relations (pp. 307-331). Cambridge University Press.

Sidanius, J., \& Pratto, F. (1999). Social dominance: An intergroup theory of social hierarchy and oppression. Cambridge University Press. 
Stangor, C., Sechrist, G. B., \& Jost, J. T. (2001). Changing racial beliefs by providing consensus information. Personality and Social Psychology Bulletin, 27, 486-496.

Taylor, D. M., \& Moghaddam, F. M. (1994). Theories of intergroup relations: International social psychological perspectives. Westport, CT: Praeger.

Thomsen, L., Green, E. G. T., \& Sidanius, J. (2008). We will hunt them down: How social dominance orientation and right-wing authoritarianism fuel ethnic persecution of immigrants in fundamentally different ways. Journal of Experimental Social Psychology, 44, 1455-1464.

Wolsko, C., Park, B., \& Judd, C. M. (2006). Considering the Tower of Babel: Correlates of assimilation and multiculturalism among ethnic minority and majority groups in the United States. Social Justice Research, 19, 277-306. 


\section{Footnote}

${ }^{1}$ In the Massachusetts sample $(\alpha=.80)$, the four SDO items were measured on a scale from 1 (Strongly disagree) to 4 (Strongly agree). In the California $(\alpha=.74)$ and Connecticut ( $\alpha=.83$ ) samples, they were assessed on a scale from 1 (Strongly disagree) to 7 (Strongly agree). The SDO items were therefore standardized within each sample before being averaged together. 
Table 1

Means, Standard Deviations, and Correlations among Personal Support for Acculturation Ideologies, SDO, and Generalized Prejudice

\begin{tabular}{|c|c|c|c|c|c|}
\hline \multirow[b]{2}{*}{ Variable } & \multicolumn{5}{|c|}{$r$} \\
\hline & 1 & 2 & 3 & 4 & 5 \\
\hline 1. Assimilation & 1 & & & & \\
\hline 2. Multiculturalism & $-.37 * * *$ & 1 & & & \\
\hline 3. Colorblindness & $-.14 *$ & $.20 * * *$ & 1 & & \\
\hline 4. SDO & $.49 * * *$ & $-.42 * * *$ & $-.22 * * *$ & 1 & \\
\hline 5. Generalized Prejudice & $.39 * * *$ & $-.35 * * *$ & $-.27 * * *$ & $.36 * * *$ & 1 \\
\hline Mean & 3.47 & 4.75 & 5.40 & 2.66 & 2.96 \\
\hline Standard Deviation & 1.37 & 1.01 & .98 & 1.15 & 1.17 \\
\hline
\end{tabular}

Note. $N=298$-299. All items are measured on 7-point scales, with higher numbers indicating greater levels of the constructs.

$* p<.05 ; * * * p<.001$. 